\title{
Monetary Expansion and Stock Returns in Pakistan
}

\author{
FAZAL HUSAIN and TARIQ MAHMOOD
}

\section{INTRODUCTION}

The effect of changes in money supply on stock returns has been a matter of controversy among economists for many decades. Those in favour of presence of links between money market and stock market argue that any change in money supply creates a wealth effect which disturbs the existing equilibrium in the portfolio of investors. When they re-adjust their asset portfolio, a new equilibrium is established in which the price level of various assets is changed.

On the other hand, if the stock market is efficient, it would already have incorporated all the current and anticipated changes in money supply. Consequently, a causal relationship between changes in money supply and stock prices will not be established. Moreover if the change in money supply coincides with a corresponding change in the velocity of money, it will not have any effect on stock prices.

The pioneering work in this regard was done by Sprinkel (1964). Using the data from 1918 to 1960 , he found a strong relationship between stock prices and money supply in the United States. His conclusions, however, were mostly based upon graphical analysis.

Sprinkel's study brought many conceptual and methodological issues in the forefront. Elaborate statistical techniques were used to explore the relationship between money supply and stock prices. For example, Rozeff (1974) conducted an extensive study and concluded that U.S. stock market is efficient with respect to monetary policy. Similarly Kraft and Kraft (1977) found no causal relationship between money supply and stock returns in the States.

Ho (1983) examined the causal relationship between money supply and stock returns for six Asian-Pacific countries. ${ }^{1}$ Using monthly data and employing minimum Final Prediction Errors, he found a uni-directional causality from money supply to stock prices for Japan and Philippines but bi-directional causality for Singapore.

Fazal Husain and Tariq Mahmood are Senior Research Economist and Research Economist at the Pakistan Institute of Development Economics, Islamabad.

${ }^{1}$ The countries studied were Australia, Hong Kong, Japan, Philippines, Singapore, and Thailand. 
Habibullah and Baharumshah (1996) used a two-step trivariate co-integration approach to check whether money supply and output can be used to predict stock prices. Using monthly data on these variables they found that in Malaysian economy output, money supply and stock markets are not co-integrated. However, in a later study Habibullah (1998) found the evidence of a causality between money supply and stock returns in Malaysian economy.

This study attempts to examine the causal relationship between money supply and stock prices in Pakistan economy. The economy has been the subject of significant changes in recent years. Like other developing nations, Pakistan has taken significant steps towards the development of its capital market including opening of the market to international investors. Measures have been taken for privatisation, economic liberalisation, and easing of regulations on operation of financial institutions.

The organisation of the paper is as follows: Section II describes the sources of the data. Section III outlines the methodology employed in this study. Section IV presents analysis of the empirical results. Finally, Section V contains summary and conclusions.

\section{DATA SOURCES}

Monthly data on money supply and stock prices were used. The sample covers the period from June 1991 to June 1999. The following two measures of money supply were used.

$$
\begin{aligned}
& \text { M1 = Currency in Circulation + Demand Deposits + Other Deposits } \\
& \text { M2 = M1 + Time Deposits + Residents Foreign Currency Deposits. }
\end{aligned}
$$

The data on these measures were taken from various issues of the Monthly Statistical Bulletin of the State Bank of Pakistan. The data on stock prices were taken from the Index Numbers of Stock Exchange Securities, also published by the State Bank of Pakistan. In addition to General Index, five sectoral indices were also used for five main sectors. These are:

(i) Cotton and other Textiles.

(ii) Chemicals and Pharmaceutical.

(iii) Fuel and Energy.

(iv) Transport and Communication.

(v) Banks and other Financial Institutions.

\section{METHODOLOGY}

In the first step, the stationarity of variables included in the analysis was tested by a Unit Root test. In this context, the Augmented Dickey Fuller (ADF) test was used and three models were estimated. 
Model I (without any constant and trend)

$$
\Delta Y_{t}=\rho^{*} Y_{t-1}+\sum_{i=1}^{p} \delta_{i} \Delta Y_{t-i}+e_{t}
$$

Model II (with constant but no trend)

$$
\Delta Y_{t}=\alpha+\rho^{*} Y_{t-1}+\sum_{i=1}^{p} \delta_{i} \Delta Y_{t-i}+e_{t}
$$

Model III (with constant and trend)

$$
\Delta Y_{t}=\alpha+\beta t+\rho^{*} Y_{t-1}+\sum_{i=1}^{p} \delta_{i} \Delta Y_{t-i}+e_{t}
$$

The test was performed for all the series of money variables and stock indices were both the original series and the differences of the series were tested for stationarity.

The co-integration between the two series was tested by running the OLS regression, called the co-integrating regression:

$$
Y_{t}=\alpha+\beta X_{t}+e_{t}
$$

Then the series of residuals, $e_{t}$ from this regression was tested for stationarity. Stationarity in $e_{t}$ implies co-integration between $Y_{t}$ and $X_{t}$, and can be tested in many ways, as discussed in Engle and Granger (1987). This study applies the ADF test (defined above) and the Durbin-Watson statistic of the co-integrating regression (CRDW).

The acceptance of co-integration between two series implies that there exists a long run relationship between them. However, this relationship may be disturbed by short run deviations from equilibrium and thus an Error Correction Model (ECM) may be an appropriate framework which is an extension of the Granger causality test where an error correction term is introduced into the test, that is,

$$
\begin{aligned}
& \Delta Y_{t}=\alpha_{1}+\rho_{1} e_{t-1}+\sum_{i=1}^{p} \beta_{i} \Delta Y_{i-1}+\sum_{j=1}^{q} \delta_{j} \Delta X_{j-1} \\
& \Delta X_{t}=\alpha_{2}+\rho_{2} e_{t-1}+\sum_{i=1}^{p} \beta_{i} \Delta Y_{i-1}+\sum_{j=1}^{q} \delta_{j} \Delta X_{j-1}
\end{aligned}
$$

where $e_{t-1}$ is an error correction term representing the long run relationship. $\rho_{1}$ and $\rho_{2}$ are considered the speed of adjustment coefficients. If both coefficients are significant, 
this will suggest that both series exert long run relationship, that is, there exists a feedback mechanism between them. If, however, only $\rho_{1}$ is found to be significant, this will suggest that $X$ off drives $Y$ toward long run equilibrium but not the other way around. The lagged terms of $\Delta Y_{t}$, and $\Delta X_{t}$, appeared as explanatory variables, indicate short run dynamics or cause and effect relationship between the two series.

\section{EMPIRICAL RESULTS}

In the first step all the series were tested for the unit roots. In this context, the ADF was applied to both the original series and the first differences. The results are reported in Table 1.

Table 1

Unit Root Tests (Augmented Dickey Fuller) for the Period June 1991 - June 1999

\begin{tabular}{|c|c|c|c|c|c|c|}
\hline & \multicolumn{3}{|c|}{ Original Series } & \multicolumn{3}{|c|}{ First Differences } \\
\hline & Model I & Model II & Model III & Model I & Model II & Model III \\
\hline $\ln \mathrm{S} 1$ & -1.11 & -0.77 & -2.06 & $-7.56^{*}$ & $-7.62 *$ & $-6.92 *$ \\
\hline $\ln \mathrm{S} 2$ & 0.65 & -2.58 & -1.60 & $-7.98^{*}$ & $-7.95^{*}$ & $-8.24 *$ \\
\hline $\ln \mathrm{S} 3$ & 0.19 & -1.99 & -1.21 & $-8.05^{*}$ & $-8.00^{*}$ & $-7.76^{*}$ \\
\hline $\ln \mathrm{S} 4$ & -0.36 & -0.87 & -2.58 & $-8.94 *$ & $-8.9 *$ & $-9.46^{*}$ \\
\hline $\ln \mathrm{S} 5$ & -0.58 & -0.57 & -1.34 & -8.35 & $-8.34^{*}$ & $-7.61^{*}$ \\
\hline $\ln \mathrm{S} 6$ & -0.42 & -1.13 & -1.74 & $-7.63 *$ & $-7.59^{*}$ & $-7.14^{*}$ \\
\hline $\ln \mathrm{M} 1$ & 2.36 & -0.44 & -2.47 & $-9.61^{*}$ & $-10.07 *$ & $-8.9 *$ \\
\hline $\ln \mathrm{M} 2$ & 6.63 & -1.96 & -3.05 & $-3.59 *$ & $-10.47 *$ & $-10.41^{*}$ \\
\hline Critical Values (0.05) & -1.94 & -2.87 & -3.43 & -1.94 & -2.87 & -3.43 \\
\hline
\end{tabular}

S1 = Cotton and other Textiles, S2 = Chemicals and Pharmaceuticals, S3 = Fuel and Energy, S4 = Transport and Communication, S5 = Finance, S6 = General Index, M1 = Currency + Demand Deposits, M2 = M1 + Time Deposits + Foreign Currency Deposits

The results suggest the acceptance of the presence of unit roots in the original series indicating that none of the original series is stationary. However, the presence of unit roots is conclusively rejected in the first differences of the series for all the variables in all the models. This suggests that all the series are integrated of order one. Since all the series are integrated of the same order, there is a possible chance of co-integration among the series.

Next, co-integrating regressions were estimated and Durbin-Watson statistic were obtained and are reported in Table 2. Further, the series of residuals were obtained from each regression and ADF was applied to test for the presence of unit roots in these residuals. These results are also reported in Table 2. 
Table 2

Cointegration Tests

\begin{tabular}{lcc}
\hline (Y, X) & CRDW & ADF \\
\hline (M1, S1) & 0.183 & $-2.46^{*}$ \\
(M1, S2) & 0.034 & -0.07 \\
(M1, S3) & 0.033 & -0.73 \\
(M1, S4) & 0.191 & $-3.56^{*}$ \\
(M1, S5) & 0.074 & $-2.02^{*}$ \\
(M1, S6) & 0.065 & $-2.52^{*}$ \\
(M2, S1) & 0.104 & $-3.01^{*}$ \\
(M2, S2) & 0.005 & -1.13 \\
(M2, S3) & 0.004 & -1.12 \\
(M2, S4) & -0.596 & $-4.25^{*}$ \\
(M2, S5) & 0.027 & $-2.69^{*}$ \\
(M2, S6) & 0.020 & $-3.52^{*}$ \\
\hline
\end{tabular}

CRDW $=$ Cointegrating Regression.

Durbin-Watson Statistic.

$\mathrm{ADF}=$ Augmented Dickey Fuller Test

Critical Value for ADF is 1.94 .

The table shows that the null hypothesis of no co-integration between the two series is rejected in all cases, except for (M1, S2), (M1, S3), (M2, S2), and (M2,S3). This suggests that, in general, there exists a long run relationship between money supply and stock prices.

Finally, to explore the long run relationship between money supply and stock prices further, that is, to know the short run dynamics as well as the cause and effect relationship, the Error Correction Model was employed and the results are reported in Table 3.

The table shows the coefficient of the error correction term along with the $t$ values. The table also shows the $F$-values for the lags of the independent variable. The model was tested for three different lags, i.e., 6,12 , and 18, selected arbitrarily.

The table shows that the error term has, in general, the correct negative signs. However, these coefficients are only significant where stock prices are regressed on M2. This implies that the ECM model does not endorse the long run relationship between M1 and stock prices shown by co-integration analysis. On the other hand, the model verifies the long run relationship between M2 and stock prices and suggests a one way causation from $\mathrm{M} 2$ to stock prices.

Regarding short run effects, the lag values, shown by $F$-values, are generally insignificant. Only lag values of M2 are found significant in the case where the model is estimated for 6 months lag indicating some short run effects of M2 on stock prices. 
Table 3

Results from Error Correction Models

\begin{tabular}{|c|c|c|c|c|c|c|c|c|c|}
\hline \multirow[b]{2}{*}{$\mathrm{Y}$ on $\mathrm{X}$} & Err. Coef & $t$-value & $F$-values & Err. Coef & $t$-value & $F$-values & Err. Coef & $t$-value & $F$-values \\
\hline & \multicolumn{3}{|c|}{ Lags $=6$} & \multicolumn{3}{|c|}{ Lags $=12$} & \multicolumn{3}{|c|}{ Lags $=18$} \\
\hline $\mathrm{M} 1$ on $\mathrm{S} 1$ & -0.007 & -0.11 & 0.60 & 0.046 & 0.50 & 0.67 & -0.074 & -0.65 & 2.09 \\
\hline $\mathrm{S} 1$ on $\mathrm{M} 1$ & -0.134 & -1.95 & 1.85 & -0.180 & -1.68 & 1.09 & -0.303 & -1.98 & 1.39 \\
\hline M1 on S4 & -0.121 & -1.98 & 1.22 & -0.088 & -0.91 & 0.63 & -0.233 & -1.47 & 1.13 \\
\hline $\mathrm{S} 4$ on $\mathrm{M} 1$ & -0.206 & -1.35 & 0.78 & -0.338 & -1.44 & 0.79 & -0.811 & -1.85 & 0.48 \\
\hline M1 on S5 & 0.004 & 0.13 & 0.41 & 0.027 & 0.76 & 0.88 & 0.033 & 0.75 & 1.37 \\
\hline $\mathrm{S} 5$ on $\mathrm{M} 1$ & -0.085 & -1.33 & 0.69 & -0.162 & -1.91 & 0.54 & -0.220 & -1.89 & 0.68 \\
\hline M1 on S6 & -0.009 & -0.31 & 1.00 & 0.018 & 0.51 & 0.79 & 0.016 & 0.37 & 1.41 \\
\hline S6 on M1 & -0.049 & -1.05 & 1.56 & -0.096 & -1.67 & 1.19 & -0.165 & $-2.01 *$ & 0.89 \\
\hline $\mathrm{M} 2$ on $\mathrm{S} 1$ & -0.018 & -1.13 & 0.32 & -0.008 & -0.40 & 0.94 & 0.004 & 0.16 & 0.81 \\
\hline $\mathrm{S} 1$ on $\mathrm{M} 2$ & -0.084 & $-2.27^{*}$ & $2.48 *$ & -0.116 & $-2.32 *$ & 1.13 & -0.180 & $-2.17 *$ & 0.82 \\
\hline $\mathrm{M} 2$ on $\mathrm{S} 4$ & -0.018 & -1.01 & 0.91 & 0.000 & 0.00 & 1.81 & 0.007 & 0.15 & 0.49 \\
\hline $\mathrm{S} 4$ on $\mathrm{M} 2$ & -0.257 & $-2.98^{*}$ & 1.58 & -0.376 & $-2.96^{*}$ & 1.15 & -0.835 & $-3.07 *$ & 0.93 \\
\hline M2 on S5 & -0.014 & -1.76 & 0.35 & -0.015 & -1.25 & 1.09 & -0.039 & -1.60 & 0.66 \\
\hline $\mathrm{S} 5$ on $\mathrm{M} 2$ & -0.086 & $-2.37^{*}$ & $2.32 *$ & -0.179 & $-3.15^{*}$ & 1.59 & -0.461 & $-3.17^{*}$ & 1.24 \\
\hline M2 on S6 & -0.013 & -1.69 & 0.59 & -0.005 & -0.38 & 1.04 & -0.018 & -0.72 & 0.68 \\
\hline S6 on M2 & -0.068 & $-2.59 *$ & $2.97 *$ & -0.129 & $-2.99 *$ & 1.61 & -0.364 & $-3.15^{*}$ & 1.03 \\
\hline
\end{tabular}


Overall, the results suggest a unidirectional causality from money supply to stock prices. Specifically, changes in monetary assets, M2, cause changes in stock prices not in the long run but also in the short run. This implies that the stock market is not efficient with respect to M2 and past information regarding monetary assets can be helpful to predict movements in stock prices.

\section{SUMMARY AND CONCLUSIONS}

The objective of the paper is to examine the causal relationship between money supply and stock prices in Pakistan. Two measures of money stocks (M1 and M2) and six stock price indices (general and five sectoral) were taken for the period June 1991 to June 1999.

The co-integration analysis indicates a long run relationship between stock prices and money supply for both M1 and M2. The Error Correction Model, on the other hand, does not endorse the long run relationship between stock prices and M1. Regarding long run relationship between stock prices and M2, the model suggests a unidirectional causality running from M2 to stock prices. The model also shows the evidence of short run effects of M2 on stock prices. The analysis suggests that the stock market is not efficient with respect to money supply.

\section{REFERENCES}

Engle, R., and C. Granger (1987) Cointegration and Error Correction: Representation, Estimation, and Testing. Econometrica 251-276.

Habibullah, M., and A. Baharumshah (1996) Money, Output, Stock Prices in Malaysia:

An Application of Cointegration Tests. International Economic Journal 121-130.

Habibullah, M. (1998) Money, Output, Stock Prices in Malaysia: Further Evidence. Borneo Review 135-155.

Ho, Y., (1983) Money Supply and Equity Prices: An Empirical Note on Far Eastern Countries. Economics Letters 161-165.

Kraft, J., and A. Kraft (1977) Determinants of Common Stock Prices: A Time Series Analysis. Journal of Finance 417-725.

Rozeff, M. (1974) Money and Stock Prices. Journal of Financial Economics 245-302.

Sprinkle, B. (1964) Money and Stock Prices. Illinois.

State Bank of Pakistan (Various Issues) Statistical Bulletin.

State Bank of Pakistan (Various Issues) Index Numbers of Stock Exchange Securities. 


\section{Comments}

The paper presented by Tariq Mahmood and Fazal Husain is an attempt to understand the relationship between monetary expansion and stock returns in Pakistan. Two definitions of money, i.e. M1 and M2 have been used to test this relationship. For stock prices, in addition to general index, sectoral indices have been used for five main sectors including textile, chemicals, energy, transport and financial institutions. The traditional methodology of time-series analysis has been applied where stationarity of variables is tested by the Augmented Dickey Fuller test for three variants of the model, viz. without constant and error, with constant only and with constant and trend. After establishing co-integration between the two variables, an error correction model has been applied. The study finds that M2 caused changes in stock prices not only in the long-run but also in the short-run. This allowed the authors to suggest that stock market in Pakistan is not efficient with respect to M2 and it can be helpful for the prediction of the movement in the stock prices.

A careful reading of the paper suggests that it is a fairly simple exercise where standard techniques are applied. Testing of stationarity, cointegration and the application of an Error Correction Model is now a text book stuff which no doubt is essential but does not merit such an elaborate treatment. For a paper like this, it is not the technique which needs to be emphasised as has been done in the paper, rather the authors should have focussed on the message and the policy implications that emerge from these results. On these aspects, unfortunately the study has nothing to offer. Judging the paper as it stands, in my opinion the selection of time period for analysis is not based on any appropriate technique. Secondly, the practicability of the association between M2 and stock price is not clearly spelled out as political and economic instability in developing economies like Pakistan appears to be a serious consideration rather than simple causation. Thirdly, the study is purely statistical in nature without economic content. The authors have followed the much criticised approach of crunching of data and getting results. As indicated, they need to elaborate the implications of the empirical results in the economic and political periphery of the concerned market.

Toseef Azid

Bahauddin Zakariya University,

Multan. 